\title{
Progressive in Theory, Regressive in Practice: A Critical Race Review of AVATAR
}

\author{
Screenplay by James Cameron \\ Directed by James Cameron \\ Produced by Twentieth Century Fox Studios
}

Paul R. Ketchum

University of Oklahoma

David G. Embrick

Loyola University-Chicago

and

B. Mitch Peck

University of Oklahoma

\section{FiLm SUMmary}

Avatar (2009) is an epic science fiction film that, tackles broad social issues such as military occupation, corporatism, imperialism, racism and ethnocentrism, ethics, and environmentalism. The 162 minute film, written and directed by James Cameron (who also directed such major Hollywood hits as Titanic, The Terminator and Aliens) surpassed Titanic to become the number 1 all-time domestic box-office hit, ${ }^{1}$ earning well over 600 million domestically and 2 billion worldwide.

Avatar takes place on a fictional world named Pandora, a land rich in natural resources, the most important of which is a fictional mineral aptly named unobtanium. The setting of the movie takes place years after failed corporate attempts to subtly coerce the local indigenous population, called the $\mathrm{Na}$ 'vi, into relocating to less desirable locations on the planet. Corporate greed eventually leads to the head of a major corporate enterprise turning to the military for help in relocating the $\mathrm{Na}$ 'vi who occupy locations rich with desirable resources. The protagonist, Jake, a paraplegic marine who dreams of one day being able to walk again, is recruited by the corporation to replace his brother who was a scientist 
trained to occupy the body of one of the avatars, genetically created, remotely operated, Na'vi-human hybrids that are controlled through a computer aided, linked consciousness. Although Jake originally agrees to spy on the $\mathrm{Na}$ 'vi for the military, he quickly ends up regretting his decision after growing close to one the $\mathrm{Na}$ 'vi clans and eventually developing a relationship with the daughter of one of the clans' spiritual leader. After learning of Jake's betrayal, the marines are called in to forcibly remove the Na'vi from one of the central unobtaniun sites. The attack devastates one of the sacred sites of the Na'vi leaving Jake to discover a way to unite and mobilize all of the Na'vi clans together and eventually repel the marines and corporation from their world. Jake is fatally wounded in the ensuing battle but his life-force is transferred from his human body to his Na'vi avatar allowing him to permanently live on Pandora.

\section{Sociological Connections And Discussion}

Avatar is a futuristic take on the traditional post-Civil Rights western film (e.g., Last of the Dogmen, Dances with Wolves). Typically this story line revolves around profit-driven, technology-loving white men who are in the process of conquering the spiritual, nature loving native people, until a white savior (Vera and Gordon 2003) comes along to save the day. While this story usually involves Native Americans, a few films have applied the same story to other indigenous, non-white groups (e.g., The Last Samurai...though fighting with Custer figures into the storyline, Star Trek).

Director/Writer Cameron has cast the $\mathrm{Na}$ vi' as fantasy/futuristic Native Americans, largely through utilizing the same Native American stereotypes used in many modern westerns. For example, Tsu'Tey, the second in command of the $\mathrm{Na}$ vi' clan at the center of the story, looks strikingly similar to popular images of Iroquois warriors. He is a skilled direhorse (Pandora's version of an equine) rider and an expert archer. Borrowing from South and Central American indigenous people, the $\mathrm{Na}$ vi' also use arrows dipped in poison and use bolas as a weapon. Consistent with modern Westerns (e.g., Dances with Wolves, Last of the Dogmen), nature is seen as simple and good and technology is seen as complex and bad. The Na vi' utilize shamen such as Mo'at (the spiritual leader in the film) as interpreters for Pandora's life force, Eywa. Like so many other films, non-Whites are seen as simple and content. This seemingly positive stereotype limits both the roles and the potential of non-whites. Echoing the stereotypes of black athletes, with the expectation to be athletic but not intellectual (e.g., blacks are less likely than whites to be quarterbacks in football or coaches in any major sport), the Na vi' are physical (one of our first views of the Na vi' avatars has them playing basketball) and spiritual, but not intellectual or technologically adept. Whites, on the other hand, have no such limitations and 


\section{HUMANITY \& SOCIETY}

are portrayed as not only masters of technology, but also capable of being one with nature.

Like so many other films (Dangerous Minds, Last of the Dogmen, Amistad and The Blind Side), in Avatar, a white person is necessary to save a non-white individual or group. As in other films featuring a white savior, Avatar's white savior, Jake Sully, comes to the minority group culture with no experience or understanding, yet manages to master all things $\mathrm{Na}$ vi', not only in a very short time, but to a degree better than any $\mathrm{Na}$ vi'. The Irving Berlinesque lesson learned here is that, as whites, we can do anything you can do, only better. This is the central tragedy of white savior films. Minorities are portrayed as limited but sympathetic characters and whites are portrayed as superior, with limitless potential, and most important, necessary to solving any problems experienced by minority groups.

Bonilla-Silva (2003) defines White habitus as a "...racialized, uninterrupted socialization process that conditions and creates whites' racial taste, perceptions, feelings, and emotions and their views on racial matters" (p. 104). In media, not only does film reflect society, it also acts to reinforce what society already deems as "normal." Thus, the exclusion and stereotyping of minorities only serve to further harden the illusion that Whites (and most often, White males) are almost always superior to others. This racial issue can be witnessed within the casting of the film Avatar, where potential racial progressivism goes awry. While Cameron should be applauded for including so many minorities in major roles in this film, quantity of representation is only part of the solution to racial inequality. The quality of the representation should not be overlooked. Four of the major supporting characters in the film are played by minority actors, three of them are Black and one is Native American. Unfortunately, none of these actors are ever seen as minorities as they play CGI (computer generated imagery) $\mathrm{Na}$ 'vi. The techs in the film are mostly Asian, the avatar drivers are white, as are the leaders of both the military and the corporation in the film. Three black actors and one Native American are essentially hidden in this film. Other Black actors are in minor supporting roles. Asian actors are cast as tech experts, who answer to whites and the sole Hispanic actor is cast as the military pilot with a conscience. Avatar casting becomes a modern "separate but equal" scenario where casting becomes "casteing." Utilizing Michelle Rodriquez (Trudy Chacon) or CCH Pounder (Mo'at) as the chief scientist (played by Sigourney Weaver) or Laz Alzono (Tsu'tey) as Jake Sully (played by Sam Worthington) would better exemplify racially progressive casting. 


\section{CONCLUSION}

As film reflects society rather than drives it (Vera and Gordon 2003), we suggest the economic reality that a major motion picture must appeal to a broad, largely white audience to be successful at the box-office combined with the expectation that society will not accept color-blind storylines or casting are more likely the cause of limited racial progressiveness in Avatar, than individual issues with the film's writer/director. Consistent with the tenets of Critical Race Theory, the cause of racial inequality is at the societal level more so than the individual level (Stephancic and Delgado 2001).

This movie appears to be well meaning with an overtly progressive, social justice message, however the subtleties of how race operates in society have rarely been so clearly illustrated, even if by accident, as in this film. Ultimately, seemingly "positive" stereotypes and a white savior casting apparently supplied by "White Habitus Talent Agency" all work to undermine an attempt to project a positive message.

\section{ENDNOTES}

${ }^{1}$ Associated Press. "'Avatar' Passes 'Titanic' in Domestic Earnings: Sci-Fi Epic Tips $\$ 600$ Million at Home on Just 47th Day of Release.” Feb. 3, 2010. For a link to the story see: http://today.msnbc.msn.com/id/35222062/ns/entertainment-movies/

\section{REFERENCES}

Bonilla-Silva, Eduardo. 2003. Racism without Racists: Color-Blind Racism and the Persistence of Racial Inequality in America. Lanham, MD: Roman \& Littlefield Publishers.

Stephancic, Jean, and Richard Delgado. 2001. Critical Race Theory: An Introduction. New York, NY: New York University Press.

Vera, Hernan, and Andrew Gordon. 2003. Screen Saviors: Hollywood Fictions of Whiteness. Lanham, MD: Roman \& Littlefield Publishers. 